\title{
Partial recN gene sequencing: a new tool for identification and phylogeny within the genus Streptococcus
}

Correspondence

Véronique Roux vroux91@live.fr

\author{
Olga O. Glazunova, Didier Raoult and Véronique Roux
}

\author{
Laboratoire de Bactériologie - Virologie, Hôpital de la Timone, CNRS UMR 6236, IFR48, 264 rue \\ Saint-Pierre, 13385 Marseille, Cedex 05, France
}

Representatives of the genus Streptococcus are Grampositive, catalase-negative, non-motile cocci. They are commensals of the tegument or mucous membranes in both humans and animals. The normal presence of streptococci on the mucous membranes and the skin explains how they can frequently contaminate biological samples. Although their pathogenicity is variable, they can be responsible for meningitis, pneumonia, endocarditis and fasciitis. At the time of writing, 65 species and 12 subspecies with validly published names are recognized as members of the genus (Euzéby, 2010). Novel species are continually being isolated from human, animal and

Abbreviation: ILD, incongruence length difference.

The GenBank/EMBL/DDBJ accession numbers for the partial recN gene sequences determined in this study are EU917226-EU917315, as detailed in Supplementary Table S1, and those of the other sequences determined in this study are FJ712038-FJ712187 (Supplementary Table S4).

Strain and primer details, including details of accession numbers, and details of inter- and intraspecies divergence and phylogenetic trees for the 'anginosus' subgroup are available as supplementary material with the online version of this paper. environmental samples and have been characterized by $16 \mathrm{~S}$ rRNA gene sequence comparisons in association with phenotypic criteria (Glazunova et al., 2006; Milinovich et al., 2008; Shewmaker et al., 2007; Takada \& Hirasawa, 2008; Vela et al., 2009). The precise identification of these bacteria at the species level is quite laborious, particularly in the 'viridans' group. Streptococci were first identified based on the haemolytic reaction, group carbohydrate antigens (Lancefield serotyping) and phenotypic tests (Facklam, 2002). Commercial systems based on comparisons of phenotypic characteristics do not permit unambiguous identification at the species level, however, because of the limited number of biochemical traits that can be analysed, the variability of traits within a species, the poor reproducibility of some tests and the fact that not all species are included in the database. Therefore, it is impossible to obtain a real idea of the host-pathogen relationships of streptococci. According to Hoshino et al. (2005), the rate of correct identification of non-haemolytic streptococcal strains by commercial identification kits was below $50 \%$ and varied significantly with regard to the studied species. 
Various molecular DNA-based methods have been proposed for the identification of Streptococcus species. Genes encoding D-alanine:D-alanine ligase ( $d d l)$ (Garnier et al., 1997), autolysin (lytA) (Kawamura et al., 1999), dextranase (dex) (Igarashi et al., 2001), the $10 \mathrm{kDa}$ and $60 \mathrm{kDa}$ heatshock proteins (groESL) (Hung et al., 2005; Teng et al., 2002), the RNA subunit of endoribonuclease $\mathrm{P}(r n p B)$ (Tapp et al., 2003), elongation factor Tu (tuf) (Picard et al., 2004), quinolone resistance-determining regions of DNA gyrase $(g y r A)$ and topoisomerase subunit C (parC) (Kawamura et al., 2005) and the 16S-23S rRNA intergenic spacer region (Chen et al., 2004; Nielsen et al., 2009) have been suggested. A good candidate for identification at the species level should present enough variability between different species but little variability within a species.

Zeigler (2003) studied 32 protein-encoding genes and determined a small set of protein-encoding genes in which the percentage of similarity between isolates could assign novel strains reliably to bacterial species and replace DNADNA hybridization. This set of genes included $\mathrm{recN}$ (recombination/repair protein), thdF (GTP-binding, thiophene oxidation) and rpoA (RNA polymerase, alpha subunit). For members of the family Pasteurellaceae, sequence comparisons of these three genes were proposed to replace DNA-DNA hybridization, to estimate the genome $\mathrm{G}+\mathrm{C}$ content of a species and to infer phylogenetic analysis in association with other markers (Kuhnert \& Korczak, 2006). Sequence comparison of the $\mathrm{recN}$ gene was applied to phylogenetic analysis and the assignment of isolates to species within the genus Geobacillus and presented a resolving power that was nearly an order of magnitude greater than that of the 16S rRNA gene (Zeigler, 2005). In this study, we explored the use of partial recN gene sequence comparisons in order to investigate taxonomy and phylogeny in the genus Streptococcus. In addition, our results were compared with those obtained previously for four other genes $(r p o B$, sodA, groEL and gyrB; Glazunova et al., 2009).

The 89 streptococcal strains studied (representing 54 species and nine subspecies) were obtained from the Collection de l'Institut Pasteur (CIP, Paris, France) and the Deutsche Sammlung von Mikroorganismen und Zellkulturen (DSMZ, Braunschweig, Germany) and are listed in Supplementary Table S1 (available in IJSEM Online). Enterococcus faecalis CIP $103015^{\mathrm{T}}$ was chosen as an outgroup for phylogenetic tree reconstructions. Clinical isolates obtained by our laboratory are characterized in Table 1.

Bacterial DNA was extracted using the MagNA Pure LC DNA isolation kit III (Roche) with the MagNA Pure LC instrument, as described by the manufacturer. Primers for amplification of the $r e c N$ gene fragment $(\mathrm{recNd} / \mathrm{recNr})$ were selected from conserved regions after alignment of sequences from complete streptococcal genomes [Streptococcus pneumoniae R6 (GenBank accession no. AE007317), S. pneumoniae TIGR4 (AE005672), S. agalactiae 2603V/R (AE009948), S. pyogenes SF370 (AE004092) and S. mutans UA159
(AE014133)] and phylogenetically related bacterial genomes [Enterococcus faecalis V583 (AE016830), Lactococcus lactis Il1403 (AE005176), Listeria innocua Clip11262 (AL592022), Listeria monocytogenes EGD (AL591824) and Staphylococcus aureus N315 (BA000018)] which were available when the study was started. The PCR annealing temperature was $48{ }^{\circ} \mathrm{C}$. Other primers were designed for the sequencing reactions. Primers are described in Supplementary Table S2. Fragments of the $r p o B$, sodA, gyrB and groEL genes were amplified by PCR as described previously (Glazunova $e t$ al., 2009).

PCR products were purified using MultiScreen PCR plates (Millipore) and sequenced using a DNA sequencing kit (BigDye Terminator version 1.1 cycle sequencing kit; PE Biosystems) according to the manufacturers' instructions. Sequence products were purified and electrophoresis was performed with a 3100 Genetic Analyzer (Applied Biosystems).

Gene sequences were aligned using the multiple alignment program CLUSTAL_X version 1.8 (Thompson et al., 1997). Phylogenetic relationships were determined using MEGA version 4 (Tamura et al., 2007). Distance matrices were determined following the assumptions described by Kimura (1980) and were used to reconstruct dendrograms using the neighbour-joining method (Saitou \& Nei, 1987). The maximum-parsimony algorithm was also used for phylogenetic analysis (Farris, 1970). Phylogenetic trees were also calculated by the maximum-likelihood method using the program DNAML in the PHYLIP software package (Felsenstein, 1989). The percentage of similarity between nucleotide sequences was calculated using BioEdit software. Bootstrap values were obtained for a consensus tree based on 100 randomly generated trees. DNA sequences of clinical isolates were compared using the BLAST2 program (Altschul et al., 1990) (http://www.ncbi.nlm.nih.gov/ blast/bl2seq/wblast2.cgi) with our local database.

The TaxonGap software tool (Slabbinck et al., 2008) was applied to represent the resolution of the gene within and between taxonomic units. TaxonGap represents the $s$ heterogeneity and $s$-separability values as light-grey and dark-grey horizontal bars, respectively, for individual biomarkers. The same scale is used to plot both $s$ heterogeneity and $s$-separability in order to support optimal comparability of the values across the biomarkers. The name of the closest neighbour is identified to the right of the dark-grey bar. Distances used for the calculation of $s$ heterogeneity and $s$-separability values were determined using pairwise nucleotide sequence alignments with MEGA version 4.

To investigate incongruence between the $r e c N$ data and the dataset for each gene sequence, the incongruence length difference (ILD) test of Farris et al. (1994) was performed using the PAUP 4.0 beta version (Swofford, 1998). The maximum-parsimony trees exploited for the ILD test were obtained from parsimony-informative sites determined using MEGA version 4. 
Table 1. Identification of clinical isolates and reference strains of $S$. anginosus, S. constellatus and S. intermedius using phylogenetic analysis and BLAST comparison

Analysis resulted in identification as: SA, S. anginosus; SC, S. constellatus; SI, S. intermedius. Strains that could not be identified by phylogenetic analysis were identified by BLAST comparison, with identifications given in parentheses. NK, Not known.

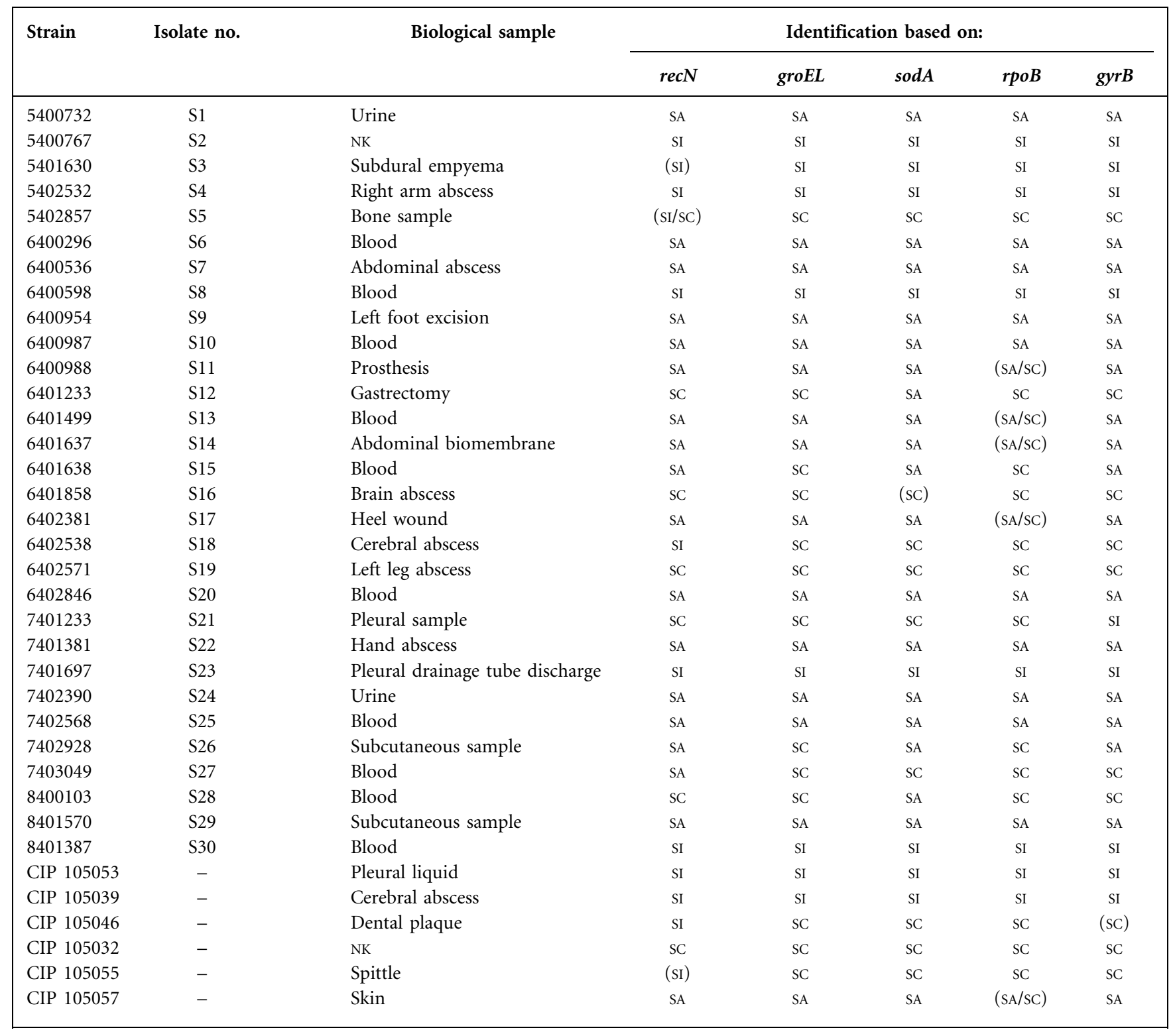

\section{Phylogeny of streptococci derived from partial recN sequences}

The sequenced fragment represented $75.3 \%$ of the full-length $r e c N$ gene sequence of S. mutans UA159 (NP_721018). A $1249 \mathrm{bp}$ fragment was amplified from the majority of the 89 streptococcal strains studied using the $r e c N$ primers designed in this study, with the exception of the fragment from Streptococcus gallinaceus CIP $107087^{\mathrm{T}}$, which was $1246 \mathrm{bp}$. A fragment of only 1212 bp was amplified from Streptococcus parauberis CIP $103956^{\mathrm{T}}$ as a result of unsuccessful sequencing of the $3^{\prime}$ end of the gene. Accession numbers for all submitted sequences are given in Supplementary Table S1.
Phylogenetic analysis was inferred from partial $\mathrm{recN}$ sequences using the neighbour-joining, maximumparsimony and maximum-likelihood methods. Identical organization was obtained for the three analyses with slight variations. The highest bootstrap values were obtained for the tree inferred from the neighbour-joining method and therefore we have concentrated on this analysis in the discussion. The neighbour-joining phylogenetic tree for type strains of species and subspecies is presented in Fig. 1.

Compared with the phylogenetic trees inferred from previously described sequence comparisons of various genes, the tree inferred from sequence comparison of the 


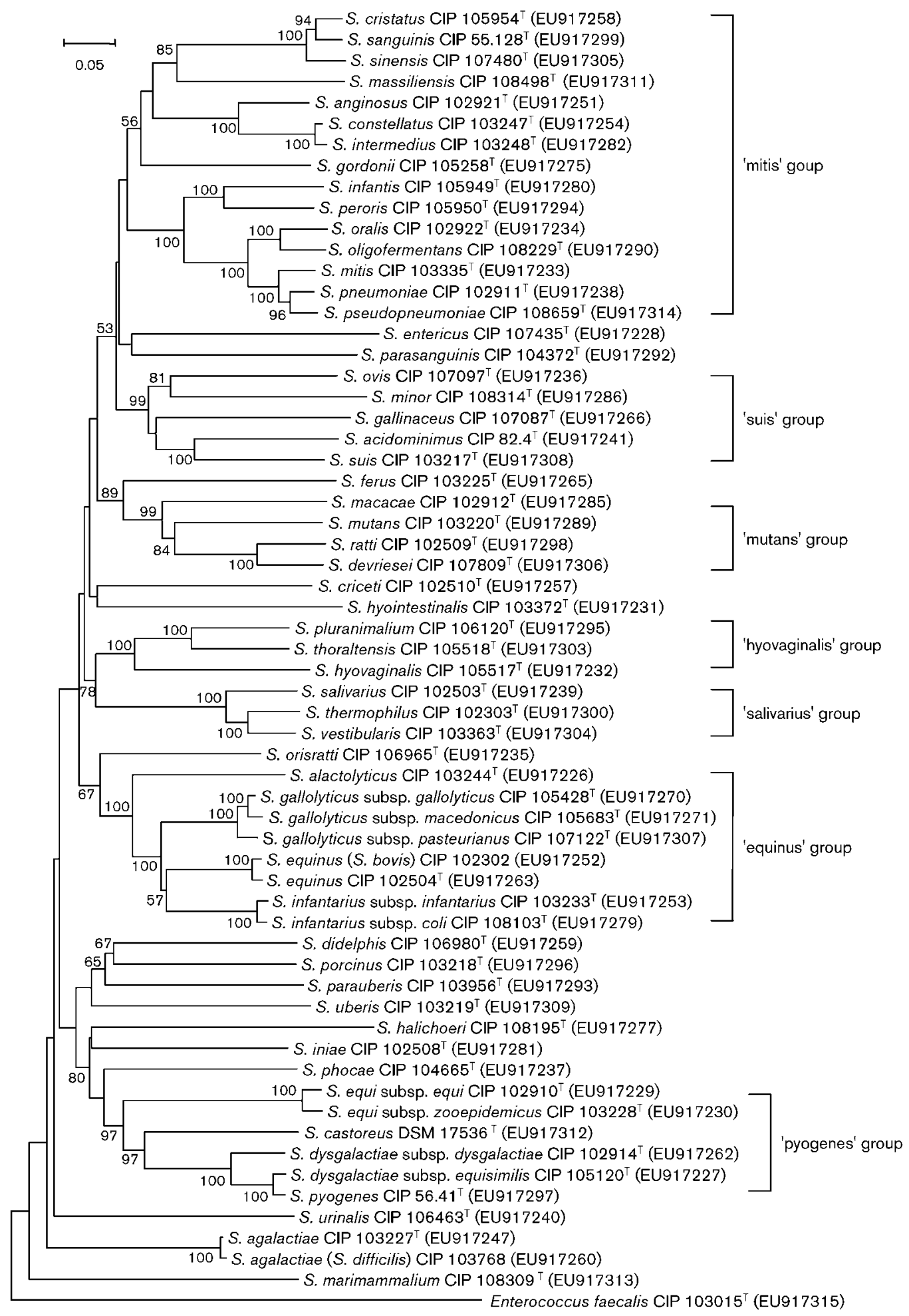

Fig. 1. Phylogenetic tree of members of the genus Streptococcus inferred from comparison of partial recN gene sequences using the neighbour-joining method. Bar, 0.05 changes per nucleotide position. The sequence of Enterococcus faecalis CIP $103015^{\top}$ was used as the outgroup. Bootstrap values $\geqslant 50$ (from 100 replicates) are indicated. 
$r e c N$ gene resulted in the most stable nodes. The numbers of nodes presenting bootstrap values higher than 50,80 and $95 \%$ are detailed in Table 2. In the recN tree, 29 $(49.2 \%)$ nodes presented bootstrap values $\geqslant 95 \%$, which was higher than the value found for groEL (24, 40.7\%), which we had considered the best tool for inference of phylogenetic relationships of streptococci in a previous study (Glazunova et al., 2009).

Although the representatives of the 'mitis' group formed the major cluster, it was not supported by a significant bootstrap value. Three subgroups were observed and were supported by high bootstrap values. The first included Streptococcus cristatus, S. sanguinis and S. sinensis, the second included Streptococcus anginosus, S. intermedius and S. constellatus and the third included Streptococcus infantis, S. peroris, S. oralis, S. oligofermentans, S. pneumoniae, S. pseudopneumoniae and S. mitis. In addition, Streptococcus parasanguinis and S. entericus grouped together, and Streptococcus gordonii and $S$. massiliensis were found as singletons.

Six other clusters were noted: (i) Streptococcus thermophilus, S. vestibularis and S. salivarius; (ii) the representatives of the 'equinus' group, which included Streptococcus alactolyticus, S. gallolyticus subsp. gallolyticus, S. gallolyticus subsp. pasteurianus, S. gallolyticus subsp. macedonicus, S. infantarius subsp. infantarius, S. infantarius subsp. coli and $S$. equinus; (iii) Streptococcus hyovaginalis, S. pluranimalium and S. thoraltensis; (iv) Streptococcus pyogenes, S. dysgalactiae subsp. dysgalactiae, S. dysgalactiae subsp. equisimilis, S. equi subsp. equi, S. equi subsp. zooepidemicus and S. castoreus; (v) the representatives of the 'mutans' group, which included Streptococcus mutans, S. macacae, S. devriesei and S. ratti; and (vi) Streptococcus suis, S. acidominimus, S. gallinaceus, S. minor and S. ovis. All of the other species clustered with nonsignificant bootstrap values at the nodes.

In the tree constructed by the maximum-parsimony method, the same clusters were noted. By this method, S. entericus was

Table 2. Nodes that presented bootstrap values greater than the indicated threshold values

Bootstrap values were calculated from 100 trees. Corresponding percentages of all nodes in the trees are indicated in parentheses. Phylogenetic trees were inferred from different genetic targets using the neighbour-joining method. Accession numbers of the sequences used are listed in Supplementary Table S1 and by Glazunova et al. (2009).

\begin{tabular}{|lccc|}
\hline \multirow{2}{*}{ Gene } & \multicolumn{3}{c|}{ Bootstrap values } \\
\cline { 2 - 4 } & $\geqslant \mathbf{5 0}$ & $\geqslant \mathbf{8 0}$ & $\geqslant \mathbf{9 5}$ \\
\hline recN & $42(71.2)$ & $35(59.3)$ & $29(49.2)$ \\
$\operatorname{groEL}$ & $38(64.4)$ & $32(54.2)$ & $24(40.7)$ \\
$\operatorname{gyr} B$ & $40(67.8)$ & $25(42.4)$ & $17(28.8)$ \\
$\operatorname{rpoB} B$ & $33(55.9)$ & $22(37.3)$ & $15(25.4)$ \\
$\operatorname{sod} A$ & $34(57.6)$ & $21(35.6)$ & $17(28.8)$ \\
\hline
\end{tabular}

not included in the 'mitis' group but rather was closely related to the 'mutans' group, even though the bootstrap value at the node was not significant $(20 \%)$. S. equi and S. castoreus were closely related to the 'pyogenes' group, but the bootstrap values at the nodes were low (56 and 54\%, respectively). In the tree constructed by the maximumlikelihood method, the major groups were congruent with those obtained using the neighbour-joining method and were supported by statistically significant bootstrap values that ranged from 85 to $100 \%$. Slight modifications were noted in the 'mitis' group. S. massiliensis was closely related to the 'anginosus' subgroup, but the bootstrap value at the node was low $(60 \%)$. S. gordonii grouped with the 'cristatus' subgroup, also with a low bootstrap value (59\%).

Compared with the tree obtained from sequence comparison of the groEL gene fragment (Glazunova et al., 2009), some differences were noted. S. acidominimus and S. suis were not included in the 'mitis' group and clustered with $S$. gallinaceus, S. minor and S. ovis. Streptococcus ferus was closely related to the 'mutans' group with a bootstrap value of $89 \%$. S. equi clustered with S. pyogenes, S. dysgalactiae and $S$. castoreus. In the 'mitis' group, $S$. gordonii did not cluster with S. sanguinis, S. cristatus and S. sinensis. The other groups or subgroups that were described for phylogenetic analysis inferred from $\mathrm{recN}$ sequence comparisons were identical to those inferred from groEL sequence comparisons (Glazunova et al., 2009).

To improve some of these inconsistencies, we considered concatenating the sequences that were obtained from different gene fragments. Most systematists consider data partitions to be combinable if they are not strongly incongruent with one another and use tests, such as the ILD test, to evaluate incongruence (Planet, 2006). Our results from the ILD test demonstrated no congruence between the $\operatorname{recN}$ data and the data for the previously studied genes (not shown). Therefore, we did not concatenate sequences that were obtained from different genes.

\section{Sequence similarity for streptococcal species}

The TaxonGap output for the Streptococcus species that were studied by recN gene sequence comparisons is shown in Fig. 2. The s-separability is a measure of the divergence between the different species, which is subsequently referred to as interspecies divergence. The s-heterogeneity is a measure of the heterogeneity between different isolates of the same species, which is subsequently referred to as intraspecies divergence. The left panel shows a neighbourjoining tree inferred from sequence comparison of partial $r e c N$ genes of type strains.

The similarity of the $r e c N$ sequences between members of different species ranged from $56.4 \%$ between Streptococcus halichoeri and S. entericus to $98.2 \%$ between S. constellatus and S. intermedius. Compared to previously studied genes, $r e c N$ gene sequence comparisons presented lower mean similarity values between different species (Table 3 ). 

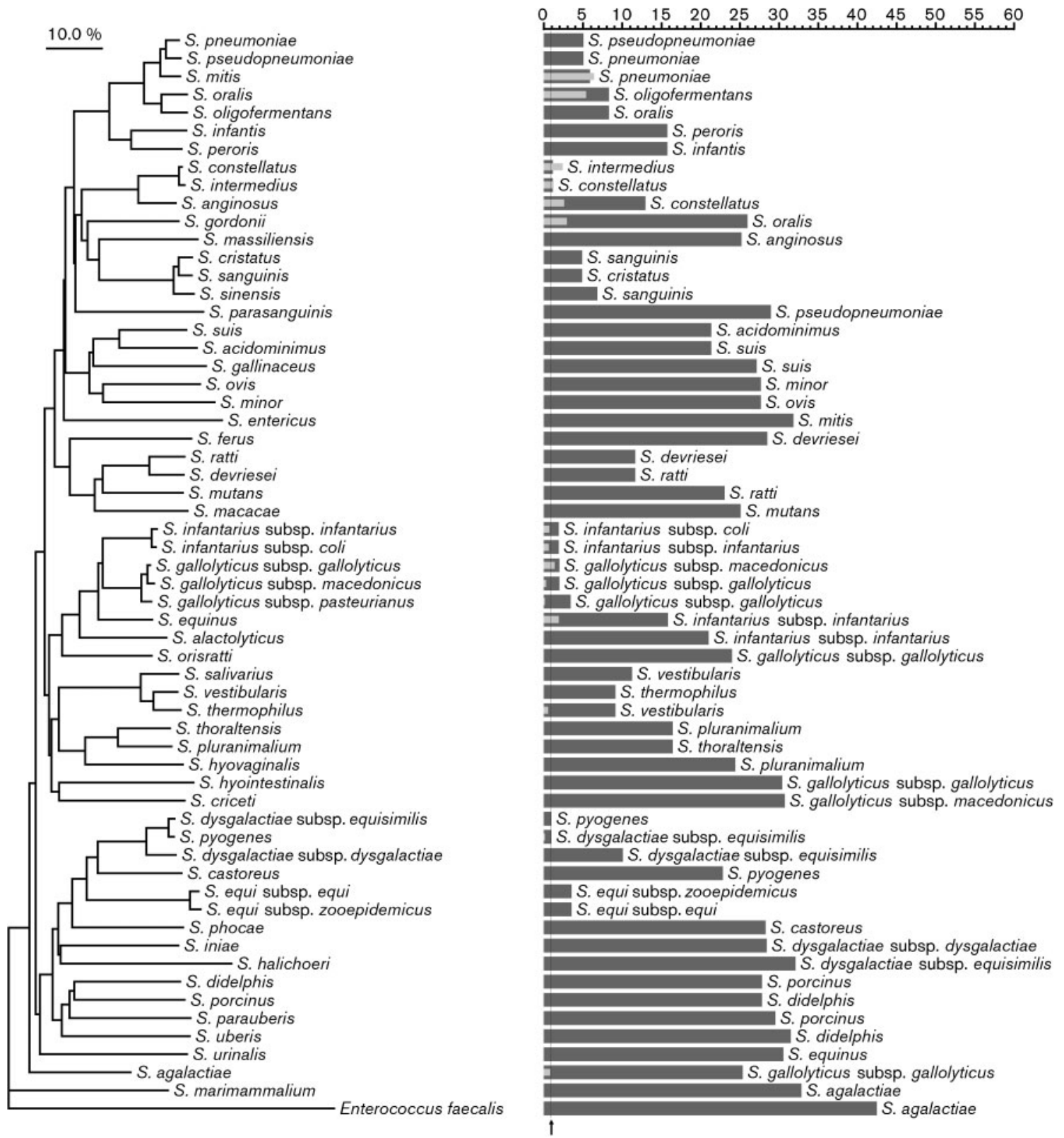

Fig. 2. TaxonGap output for Streptococcus species studied by partial recN gene sequence comparison. The left panel shows a neighbour-joining tree inferred from partial $r e c N$ gene sequence comparison. For each of the species in the phylogenetic tree, the right panel depicts the interspecies and intraspecies variability. Separability values between different species are represented as dark-grey bars with the names of the closest relatives. Heterogeneity values among isolates of the same species are represented as pale-grey bars.

Sequence comparison of the partial $\operatorname{rec} N$ gene was also applied to streptococci at the subspecies level. In the genus Streptococcus, most of the subspecies were highly related (95.6-98\%).The most closely related subspecies were $S$. gallolyticus subsp. gallolyticus and S. gallolyticus subsp. macedonicus (98\%) and the least closely related subspecies were S. dysgalactiae subsp. dysgalactiae and S. dysgalactiae subsp. equisimilis ( $89.8 \%)$. Higher mean divergence values between subspecies were obtained with the sodA gene than with the $\operatorname{recN}$ gene (Tables 3 and 4 ). Fewer than $1 \%$ of species and subspecies pairs exhibited levels of sequence similarity $\geqslant 90 \%$. The majority of species and subspecies pairs $(85.6 \%)$ were situated in the range of $60-70 \%$ similarity. Several isolates from some species or subspecies were studied: S. mitis (3), S. oralis (2), S. constellatus (3), S. intermedius (3), S. anginosus (2), S. gordonii (2), S. infantarius subsp. coli (2), S. infantarius subsp. infantarius (3), S. gallolyticus subsp. macedonicus (2), S. gallolyticus 
Table 3. Nucleotide sequence similarities between species and divergence between subspecies of the genus Streptococcus

Values are means with minimum-maximum ranges in parentheses. Accession numbers of the sequences used are listed in Supplementary Table S1 and by Glazunova et al. (2009).

\begin{tabular}{|lcl|}
\hline Gene & $\begin{array}{c}\text { Interspecies } \\
\text { similarity (\%) }\end{array}$ & $\begin{array}{c}\text { Intersubspecies } \\
\text { divergence (\%) }\end{array}$ \\
\hline 16S rRNA & $94.1(88.8-99.7)$ & $1.11(0.03-2.1)$ \\
rpoB & $84.6(76.1-97.6)$ & $1.31(0.57-2.1)$ \\
sodA & $74.8(63.6-100)$ & $5.92(1.2-12.9)$ \\
groEL & $78.1(72.6-96.6)$ & $2.96(1.2-6.1)$ \\
gyrB & $73.2(64.6-97.5)$ & $3.29(1.6-6.5)$ \\
$\operatorname{recN}$ & $66.6(56.4-98.2)$ & $4.32(1.9-10.2)$ \\
\hline
\end{tabular}

subsp. gallolyticus (4), S. gallolyticus subsp. pasteurianus (3), S. equinus (3) and S. agalactiae (8). Although only relatively few isolates were studied, the intraspecies variability seemed low for most species $(<4 \%)$, with the exception of $S$. mitis $(6.7 \%)$. These observations will need to be confirmed by studying more isolates.

In the phylogenetic analysis inferred from the $r e c N$ gene sequence comparison, the two subspecies of $S$. dysgalactiae did not cluster together. The species $S$. dysgalactiae was proposed by Garvie et al. (1983), and its description was amended by Farrow \& Collins (1984). The latter authors showed, based on DNA-DNA hybridization, that the species 'Streptococcus equisimilis' should be included in S. dysgalactiae. Two subpopulations of this species were subsequently characterized by Vandamme et al. (1996), from which two subspecies, S. dysgalactiae subsp. dysgalactiae (animal origin) and $S$. dysgalactiae subsp. equisimilis (human origin), were proposed. A multilocus enzyme electrophoresis study confirmed the existence of the two subgroups in S. dysgalactiae, but the isolates included in each subspecies differed (Vieira et al., 1998). In our study, the divergence between the two subspecies of $S$. dysgalactiae was high $(10.2 \%)$. This particular divergence was the highest for each of the gene sequence comparisons: groEL (6.1\%), rpoB $(2.1 \%)$ and $\operatorname{sod} A(12.9 \%)$. The values found for other genes are reported in Table 4. DNA-DNA hybridization is considered the standard reference technique in bacterial identification. Values $\geqslant 70 \%$ (commonly held as the threshold value) were found for strains of the two subspecies of S. dysgalactiae by Farrow \& Collins (1984) (92-99\%) and Vieira et al. (1998) (75-77\%), although the reported values are very different. Therefore, $S$. dysgalactiae subsp. dysgalactiae and S. dysgalactiae subsp. equisimilis are representatives of the same species, although genetic analysis of more isolates could improve their clustering into subspecies.

\section{The 'anginosus' subgroup}

Another interesting result of this study was the high similarity between $S$. constellatus and S. intermedius. S. anginosus, S. constellatus and S. intermedius were described in 1906, 1924 and 1925, respectively. Previous studies have shown considerable genetic similarity within the group, even though it is biochemically heterogeneous (Farrow \& Collins, 1984; Coykendall et al., 1987), and proposed that the three species should be included in a single species. Based on DNA-DNA hybridization, Whiley \& Beighton (1991) again proposed the recognition of three distinct species. However, a lack of reciprocity was observed in the levels of DNA relatedness between the type strains of $S$. intermedius and $S$. constellatus (36 and $65 \%$ ). Taken together, these observations demonstrated the complexity in defining species within the 'anginosus' subgroup. To understand better the phylogenetic evolution of this group, we determined the sequences of the recN, groEL, gyrB, sodA and $r p o B$ genes for 30 clinical strains isolated in our laboratory as well as isolates of S. anginosus (1), S. intermedius (2) and S. constellatus (3) obtained from the CIP collection (Supplementary Table S3). Two approaches were used to identify the isolates at the species level: phylogenetic analysis (Supplementary Fig. S1) and BLAST comparison when identification by phylogenetic analysis was impossible. In the phylogenetic analysis, sequences that grouped into one cluster with a significant bootstrap value at the corresponding node $(>85 \%)$ were considered to belong to the same species. Sequences that were isolated or which grouped on separated branches with non-significant bootstrap values at the corresponding nodes were subjected to analysis by the BLAST program. Strain identifications are detailed in Table 1. Two strains identified as S. anginosus in the CIP, strains CIP 103053 and CIP

Table 4. Nucleotide sequence divergence between subspecies

\begin{tabular}{|c|c|c|c|c|c|c|}
\hline \multirow[t]{2}{*}{ Subspecies comparison } & \multicolumn{6}{|c|}{ Mean divergence $(\%)$} \\
\hline & $\operatorname{recN}$ & groEL & $\operatorname{gyr} B$ & rрoв & $\operatorname{sod} A$ & 16S rRNA \\
\hline S. dysgalactiae subsp. dysgalactiae vs subsp. equisimilis & 10.2 & 6.1 & 3.3 & 2.1 & 12.9 & 1.3 \\
\hline S. equi subsp. equi vs subsp. zooepidemicus & 3.7 & 1.6 & 1.6 & 2.0 & 1.2 & 2.1 \\
\hline S. infantarius subsp. infantarius vs subsp. coli & 2.1 & 2.93 & 6.5 & 1.42 & 10.27 & 0.03 \\
\hline S. gallolyticus subsp. gallolyticus vs subsp. macedonicus & 2.0 & 1.08 & 2.17 & 0.67 & 2.1 & 1.45 \\
\hline S. gallolyticus subsp. gallolyticus vs subsp. pasteurianus & 3.5 & 1.52 & 2.7 & 0.57 & 3.97 & 0.95 \\
\hline S. gallolyticus subsp. macedonicus vs subsp. pasteurianus & 4.4 & 2.33 & 3.5 & 1.1 & 5.1 & 0.8 \\
\hline
\end{tabular}


103055, grouped with the species $S$. intermedius and $S$. constellatus, respectively. Identification at the species level ( $S$. intermedius) was impossible using recN gene sequence comparison for isolate S5. Isolates of S. constellatus and S. intermedius clustered in the phylogenetic tree inferred from sequence comparisons of the $\operatorname{recN} \mathrm{N}$, groEL, sodA and $\operatorname{gyr} B$ genes (Supplementary Fig. S1). Using $r p o B$ gene sequence comparison, the type strain of S. intermedius, CIP $103248^{\mathrm{T}}$, clustered with the 'anginosus' species isolates, and another cluster included the other isolates that represented $S$. intermedius. However, this cluster was not related to the cluster that included the $S$. constellatus isolates. The identification of $S$. anginosus and $S$. constellatus isolates was more difficult using $r p o B$ gene sequence comparison, as it was impossible to identify five isolates ( $\mathrm{S} 11, \mathrm{~S} 13, \mathrm{~S} 14, \mathrm{~S} 17$ and CIP 105057) at the species level. Identification of two isolates (S15 and S26) was impossible at the species level; they were identified as either $S$. anginosus or $S$. constellatus, depending on which gene sequence was analysed. To try to explain the difficulty in differentiating isolates of $S$. anginosus and $S$. constellatus, inter- and intraspecies percentages of divergence were calculated for each species and for each gene (Supplementary Table S4). The interspecies divergence was lower for S. intermedius/S. constellatus and the intraspecies divergence was higher for $S$. anginosus. The most likely explanation is that genetic recombination has occurred between some isolates of S. anginosus and S. constellatus.

\section{Conclusions}

Partial sequence comparison of the $r e c N$ gene differentiates members of the genus Streptococcus clearly and allows phylogenetic relationships between the different species to be inferred with a high level of statistical support. In comparison with previously studied genes (16S rRNA, groEL, gyrB, rpoB and $\operatorname{sod} A$ ), $r e c N$ represents the best tool to identify streptococci and to study evolution in this group of bacteria. Six clusters are well defined: the 'pyogenes' group, the 'equinus' group, the 'salivarius' group, the 'mutans' group, the 'hyovaginalis' group and the 'suis' group. In general, however, the streptococci constitute a heterogeneous group, as the phylogenetic position of many representatives differs with the studied gene. DNA-DNA hybridization has been the 'goldstandard' method for identification at the species level, but partial gene sequencing analyses highlight some peculiarities, such as the high divergence between $S$. dysgalactiae subsp. dysgalactiae and $S$. dysgalactiae subsp. equisimilis or the high similarity between $S$. intermedius and $S$. constellatus. In the past, contradictory results have been published concerning these species and subspecies and, in future, the use of new approaches could result in re-evaluation of their taxonomic status.

\section{References}

Altschul, S. F., Gish, W., Miller, W., Myers, E. W. \& Lipman, D. J. (1990). Basic local alignment search tool. J Mol Biol 215, 403-410.
Chen, C. C., Teng, L. J. \& Chang, T. C. (2004). Identification of clinically relevant viridans group streptococci by sequence analysis of the 16S-23S ribosomal DNA spacer region. J Clin Microbiol 42, 26512657.

Coykendall, A. L., Wesbecher, P. M. \& Gustafson, K. B. (1987). "Streptococcus milleri", Streptococcus constellatus, and Streptococcus intermedius are later synonyms of Streptococcus anginosus. Int J Syst Bacteriol 37, 222-228.

Euzéby, J. P. (2010). Streptococcus Rosenbach 1884, genus. In List of Bacterial Names with Standing in Nomenclature. http://www.bacterio. cict.fr/s/streptococcus.html

Facklam, R. (2002). What happened to the streptococci: overview of taxonomic and nomenclature changes. Clin Microbiol Rev 15, 613630.

Farris, J. S. (1970). Methods for computing Wagner trees. Syst Zool 19, 83-92.

Farris, J. S., Kallersjo, M., Kluge, A. G. \& Bult, C. (1994). Testing significance of incongruence. Cladistics 10, 315-319.

Farrow, J. A. E. \& Collins, M. D. (1984). Taxonomic studies on streptococci of serological groups $\mathrm{C}, \mathrm{G}$ and $\mathrm{L}$ and possibly related taxa. Syst Appl Microbiol 5, 483-493.

Felsenstein, J. (1989). PHYLIP - phylogeny inference package (version 3.2). Cladistics 5, 164-166.

Garnier, F., Gerbaud, G., Courvalin, P. \& Galimand, M. (1997). Identification of clinically relevant viridans group streptococci to the species level by PCR. J Clin Microbiol 35, 2337-2341.

Garvie, E. I., Farrow, J. A. E. \& Bramley, A. J. (1983). Streptococcus dysgalactiae (Diernhofer) nom. rev. Int J Syst Bacteriol 33, 404-405.

Glazunova, O. O., Raoult, D. \& Roux, V. (2006). Streptococcus massiliensis sp. nov., isolated from a patient blood culture. Int J Syst Evol Microbiol 56, 1127-1131.

Glazunova, O. O., Raoult, D. \& Roux, V. (2009). Partial sequence comparison of the $r p o B$, sodA, groEL, and gyrB genes within the genus Streptococcus. Int J Syst Evol Microbiol 59, 2317-2322.

Hoshino, T., Fujiwara, T. \& Kilian, M. (2005). Use of phylogenetic and phenotypic analyses to identify nonhemolytic streptococci isolated from bacteremic patients. J Clin Microbiol 43, 6073-6085.

Hung, W. C., Tsai, J. C., Hsueh, P. R., Chia, J. S. \& Teng, L. J. (2005). Species identification of mutans streptococci by groESL gene sequence. J Med Microbiol 54, 857-862.

Igarashi, T., Ichikawa, K., Yamamoto, A. \& Goto, N. (2001). Identification of mutans streptococcal species by the PCR products of the dex genes. J Microbiol Methods 46, 99-105.

Kawamura, Y., Whiley, R. A., Shu, S. E., Ezaki, T. \& Hardie, J. M. (1999). Genetic approaches to the identification of the mitis group within the genus Streptococcus. Microbiology 145, 2605-2613.

Kawamura, Y., Itoh, Y., Mishima, N., Ohkusu, K., Kasai, H. \& Ezaki, T. (2005). High genetic similarity of Streptococcus agalactiae and Streptococcus difficilis: S. difficilis Eldar et al. 1995 is a later synonym of S. agalactiae Lehmann and Neumann 1896 (Approved Lists 1980). Int J Syst Evol Microbiol 55, 961-965.

Kimura, M. (1980). A simple method for estimating evolutionary rates of base substitutions through comparative studies of nucleotide sequences. J Mol Evol 16, 111-120.

Kuhnert, P. \& Korczak, B. M. (2006). Prediction of whole-genome DNA-DNA similarity, determination of $\mathrm{G}+\mathrm{C}$ content and phylogenetic analysis within the family Pasteurellaceae by multilocus sequence analysis (MLSA). Microbiology 152, 2537-2548.

Milinovich, G. J., Burrell, P. C., Pollitt, C. C., Bouvet, A. \& Trott, D. J. (2008). Streptococcus henryi sp. nov. and Streptococcus caballi sp. nov., 
isolated from the hindgut of horses with oligofructose-induced laminitis. Int J Syst Evol Microbiol 58, 262-266.

Nielsen, X. C., Justesen, U. S., Dargis, R., Kemp, M. \& Christensen, J. J. (2009). Identification of clinically relevant nonhemolytic streptococci on the basis of sequence analysis of 16S-23S intergenic spacer region and partial $g d h$ gene. J Clin Microbiol 47, 932-939.

Picard, F. J., Ke, D., Boudreau, D. K., Boissinot, M., Huletsky, A., Richard, D., Ouellette, M., Roy, P. H. \& Bergeron, M. G. (2004). Use of tuf sequences for genus-specific PCR detection and phylogenetic analysis of 28 streptococcal species. J Clin Microbiol 42, 3686-3695.

Planet, P. J. (2006). Tree disagreement: measuring and testing incongruence in phylogenies. J Biomed Inform 39, 86-102.

Saitou, N. \& Nei, M. (1987). The neighbor-joining method, a new method for reconstructing phylogenetic trees. Mol Biol Evol 4, 406-425.

Shewmaker, P. L., Camus, A. C., Bailiff, T., Steigerwalt, A. G., Morey, R. E. \& Carvalho, M. G. S. (2007). Streptococcus ictaluri sp. nov., isolated from Channel catfish Ictalurus punctatus broodstock. Int J Syst Evol Microbiol 57, 1603-1606.

Slabbinck, B., Dawyndt, P., Martens, M., De Vos, P. \& De Baets, B. (2008). TaxonGap: a visualization tool for intra- and inter-species variation among individual biomarkers. Bioinformatics 24, 866-867.

Swofford, D. L. (1998). Phylogenetic analysis using parsimony (PAUP), version 4. Sunderland, MA: Sinauer Associates.

Takada, K. \& Hirasawa, M. (2008). Streptococcus dentirousetti sp. nov., isolated from the oral cavities of bats. Int J Syst Evol Microbiol 58, 160-163.

Tamura, K., Dudley, J., Nei, M. \& Kumar, S. (2007). MEGA4: molecular evolutionary genetics analysis (MEGA) software version 4.0. Mol Biol Evol 24, 1596-1599.

Tapp, J., Thollesson, M. \& Herrmann, B. (2003). Phylogenetic relationships and genotyping of the genus Streptococcus by sequence determination of the RNase P RNA gene, rmpB. Int J Syst Evol Microbiol 53, 1861-1871.

Teng, L. J., Hsueh, P. R., Tsai, J. C., Chen, P. W., Hsu, J. C., Lai, H. C., Lee, C. N. \& Ho, S. W. (2002). groESL sequence determination, phylogenetic analysis, and species differentiation for viridans group streptococci. J Clin Microbiol 40, 3172-3178.

Thompson, J. D., Gibson, T. J., Plewniak, F., Jeanmougin, F. \& Higgins, D. G. (1997). The CLUSTAL_X windows interface: flexible strategies for multiple sequence alignment aided by quality analysis tools. Nucleic Acids Res 25, 4876-4882.

Vandamme, P., Pot, B., Falsen, E., Kersters, K. \& Devriese, L. A. (1996). Taxonomic study of Lancefield streptococcal groups C, G, and L (Streptococcus dysgalactiae) and proposal of S. dysgalactiae subsp. equisimilis subsp. nov. Int J Syst Bacteriol 46, 774-781.

Vela, A. I., Casamayor, A., Sánchez del Rey, V., Dominguez, L. \& Fernández-Garayzábal, J. F. (2009). Streptococcus plurextorum sp. nov., isolated from pigs. Int J Syst Evol Microbiol 59, 504-508.

Vieira, V. V., Teixeira, L. M., Zahner, V., Momen, H., Facklam, R. R., Steigerwalt, A. G., Brenner, D. J. \& Castro, A. C. (1998). Genetic relationships among the different phenotypes of Streptococcus dysgalactiae strains. Int J Syst Bacteriol 48, 1231-1243.

Whiley, R. A. \& Beighton, D. (1991). Emended descriptions and recognition of Streptococcus constellatus, Streptococcus intermedius, and Streptococcus anginosus as distinct species. Int J Syst Bacteriol 41, $1-5$.

Zeigler, D. R. (2003). Gene sequences useful for predicting relatedness of whole genomes in bacteria. Int J Syst Evol Microbiol 53, 18931900.

Zeigler, D. R. (2005). Application of a recN sequence similarity analysis to the identification of species within the bacterial genus Geobacillus. Int J Syst Evol Microbiol 55, 1171-1179. 